\title{
Replacing foods high in saturated fat by low-saturated fat alternatives: a computer simulation of the potential effects on reduction of saturated fat consumption
}

\author{
Bilbo Schickenberg ${ }^{1}$, Patricia van Assema ${ }^{1}$, Johannes Brug ${ }^{2}$, Janneke Verkaik-Kloosterman $^{3}$, \\ Marga C. Ocké ${ }^{3}$ and Nanne K. de Vries ${ }^{1}$ \\ ${ }^{1}$ Department of Health Promotion, Nutrition and Toxicology Research Institute Maastricht (NUTRIM), Maastricht University, \\ Maastricht, The Netherlands \\ ${ }^{2}$ EMGO Institute for Health and Care Research, VU University Medical Centre, Amsterdam, The Netherlands \\ ${ }^{3}$ National Institute for Public Health and the Environment (RIVM), Bilthoven, The Netherlands
}

(Received 25 April 2008 - Revised 14 November 2008 - Accepted 17 November 2008 - First published online 13 January 2009)

\begin{abstract}
This simulation study aimed to assess the change in saturated fat intake achieved by replacing one to three of the products contributing most to individual saturated fat intake by alternative products low in saturated fat. Food consumption data of 750 participants (aged 19-30 years) from a recent Dutch food consumption survey were used. For each participant, the three products (from different product groups) that contributed most to their saturated fat intake were ranked in order of diminishing contribution. These products were sequentially replaced by lower saturated fat alternatives that were available in Dutch supermarkets. Mean percentage energy (en\%) from saturated fat and energy intake in kJ per d were calculated before and after each of the three replacements. Dutch cheese, meat (for dinner) and milk were the main contributors to saturated fat intake for most participants. Starting at a mean en $\%$ from saturated fat of $12 \cdot 4$, the three replacements together resulted in a mean reduction of $4.9 \mathrm{en} \%$ from saturated fat. The percentage of participants meeting the recommendation for saturated fat $(<10$ en\%) increased from $23.3 \%$ to $86.0 \%$. We conclude that the replacement of relatively few important high-saturated fat products by available lower-saturated fat alternatives can significantly reduce saturated fat intake and increase the proportion of individuals complying with recommended intake levels.
\end{abstract}

Saturated fat reduction: Product replacement: Products low in saturated fat

In many countries, including the Netherlands, dietary recommendations for the public have been issued. The recommendations focus on the intake of various nutrients (i.e. fibre, SFA, mono trans-fatty acids, easily fermentable sugars, salt) and foods (i.e. fruit, vegetables, whole-grain cereal products, fish) ${ }^{(1)}$. The most recent Dutch food consumption survey among young adults (aged 19-30 years) indicated that it is particularly the intake of saturated fats that is higher than recommended ${ }^{(2)}$. Whereas the guidelines recommend the consumption of less than $10 \%$ of total energy intake (en\%) from saturated fat, the habitual intake of no more than an estimated $6 \%$ of the female and $11 \%$ of male participants met this recommendation in 2003 .

High intake of saturated fat has been linked to increased risk of $\mathrm{CVD}^{(3)}$, and reducing consumption of saturated fat to the recommended levels is expected to yield substantial health benefits ${ }^{(3,4)}$.

Several product groups are responsible for a high intake of saturated fat in the daily diet of the Dutch population. These product groups include dairy products (including cheese), meat and meat products, fats, bakery goods and biscuits, grain and grain products, sweets, and sauces ${ }^{(2)}$. In the last few decades, the food industry has introduced alternative food products with reduced (saturated) fat contents for virtually every product group, for example, low-fat milk, lean cheese, meat substitutes, and 'diet' margarine. Because nutrition is a complex behaviour, individuals might think that it would take great effort for them to meet the dietary recommendations. Morgan et al., however, suggest that the replacement of only a limited number of products might already result in a considerable change in macronutrient intake $^{(5)}$. The aim of the present study was therefore to assess the change in the intake of saturated fat that can theoretically be achieved by replacing one to three of the products that contribute most to an individual's saturated fat intake by food products that contain less saturated fat and are available on the Dutch food market.

In a simulation study by Kistemaker using data from the 1987-8 Dutch national food consumption survey, high-fat products (cheese, milk, meat, and fat spreads) were substituted by lean alternatives ${ }^{(6)}$. Simultaneous total replacement in all four product groups led to a mean reduction of $11.7 \mathrm{en} \%$ 
from fat in their population. Using data of men aged 22-49 years from the same dataset, Kistemaker et al. also compared the percentage energy intake from fat in men solely using lean products within a product group and in users of higher-fat products within the same product group ${ }^{(7)}$. Solely using lean products in a specific product group was associated with a higher en\% from fat from other product groups. However, despite this compensation behaviour, the use of lean products caused an overall reduction in energy intake from fat. Morgan et al. analysed the theoretical effect of fat reduction strategies within single and across multiple product groups on the macronutrient profile of a typical American $\operatorname{diet}^{(5)}$. Based on Third National Health and Nutrition Examination Survey (NHANES-III) data, $3 \mathrm{~d}$ menus were created for both men and women, designed to fit the parameters of total energy consumption and en $\%$ from fat (34 en $\%$ for both). While the mean total energy content of the meals was left unchanged, replacement of more products and more extreme replacements (for example, fat-free replacement for full-fat products) resulted in greater reductions in the en $\%$ from fat. In a small field experiment conducted in the UK, participants in the experimental group were instructed to consume reduced-fat foods ad libitum instead of the traditional highfat counterparts that they usually consumed, whereas controls were given no special instructions. The unrestricted use of reduced-fat products resulted in a reduction of fat intake to the recommended levels. Total energy intake did not differ significantly between the two groups due to compensation by energy intake from other macronutrients (carbohydrates and protein $)^{(8)}$. The $1 \%$ or less campaign in the USA aimed to reduce the total and saturated fat consumption of communities by encouraging adults and children to switch from drinking whole or $2 \%$ milk to $1 \%$ or skimmed milk. The basic idea is that if the average whole-milk drinker switches to skimmed milk, his/her saturated fat intake drops from 12 to $10 \mathrm{en} \%$. The percentage of participants reporting switching from high- to low-fat milk ranged from $13-38 \%$ in four different communities ${ }^{(9)}$. Finally, a Dutch field experiment found that participants who had the opportunity to choose ad libitum from forty-four reduced-fat foods for a period of 6 months significantly reduced their total fat intake as compared with participants who chose from fortyfour full-fat products ${ }^{(10)}$.

In contrast to these earlier studies, the present study focused on reducing the intake of saturated fat instead of total fat, recognising that total en $\%$ from fat is a less important public health target. Furthermore, only the three highest suppliers of saturated fat intake for each individual were replaced, while earlier studies either simulated replacement of all products within one or more product groups ${ }^{(5-7)}$, or offered participants ad libitum use of reduced-fat products ${ }^{(8,9)}$ without reporting the number of products that the participants actually replaced in their diet.

The specific research questions of the present study were:

(1) What reduction in en\% from saturated fat can theoretically be achieved by the replacement of up to three products from three different product groups in individuals' diets by alternatives with lower levels of SFA?

(2) What percentage of participants meets the recommendation for saturated fat intake after these replacements?
(3) What is the effect of the replacements on total energy intake?

\section{Methods}

Sample, design and procedure

Data of the 2003 Dutch food consumption survey among young adults were used ${ }^{(2)}$. Participants, aged 19-30 years, were members of consumer panels. Response was $42 \%$. The participants were considered to be representative of Dutch young adults in terms of sex, age, level of education and region of residence. Food consumption data were collected by trained dietitians using two $24 \mathrm{~h}$ dietary recalls, by means of a computer-assisted interview created with EPIC-SOFT software (IARC, Lyon, France) ${ }^{(11)}$. The period to which the questions referred was from getting up on the day before the interview until getting up on the day of the interview. A 7-14d time interval was set between the first and second interviews. The second interview was conducted on a different day of the week from the first. Participants were also asked to fill in a questionnaire on their demographics and other background variables.

The mean quantities (over the two recall days) of all products consumed were calculated for each participant. Information on energy $(\mathrm{kJ})$ and saturated fat $(\mathrm{g})$ content per $100 \mathrm{~g}$ of each product was based on the 2001 Netherlands food composition table ${ }^{(12)}$. This information was used to calculate energy and saturated fat intakes for each participant.

\section{Defining product groups}

All products consumed were classified into product groups, each of which was defined as a set of products that are comparable in several respects, such as form and function, including aspects of when (time of day) and how (preparation) a product is supposed to be used (for example, meat for dinner or as cold cuts for sandwiches). The classification of products into product groups was based for the most part on the classification of products in the 2001 Dutch food composition table ${ }^{(12)}$. If products within one product group differed too much from each other, making it impossible to replace these products by one single alternative product, subgroups were defined. For example, instead of replacing all cheeses that were being consumed by a single alternative product, the cheeses were subdivided into four subgroups (Dutch hard cheeses, Dutch soft cheeses, non-Dutch hard and non-Dutch soft cheeses) and an alternative was selected for each of these subgroups. Other subgroups were formed in the product groups of meats, pastry goods, milk and milk products, nuts and snacks, soup, candy, and fats (Table 1).

\section{Selection of alternative products}

One single alternative product was selected for each product group. The selection of alternatives aimed to include food products that resembled the products originally consumed as closely as possible in appearance and function. Alternatives had to contain less saturated fat than the traditionally consumed products and had to be available in Dutch supermarkets at the time of the study. If multiple alternatives were available 


\begin{tabular}{|c|c|c|c|c|c|c|c|c|}
\hline \multirow[b]{2}{*}{ Product group } & \multirow[b]{2}{*}{$\begin{array}{c}\text { Saturated fat } \\
(\mathrm{g} / 100 \mathrm{~g}) \dagger\end{array}$} & \multirow[b]{2}{*}{ Alternative product $\ddagger$} & \multirow[b]{2}{*}{$\begin{array}{l}\text { Saturated fat } \\
(\mathrm{g} / 100 \mathrm{~g})\end{array}$} & \multicolumn{3}{|c|}{ Replacements* } & \multirow{2}{*}{$\begin{array}{l}\text { Total percentage of replacements } \\
\text { per product group }\end{array}$} & \multirow{2}{*}{$\begin{array}{l}\text { Cumulative percentage } \\
\text { of replacements }\end{array}$} \\
\hline & & & & $1 \mathrm{st}$ & 2nd & $3 r d$ & & \\
\hline Dutch cheese & 20.5 & $10+$ cheese & $4 \cdot 2$ & 31.7 & $13 \cdot 2$ & $10 \cdot 8$ & $18 \cdot 6$ & \\
\hline Meat (for dinner) & $5 \cdot 6$ & Dairy-based meat replacer & 0.6 & 14.1 & $17 \cdot 2$ & $11 \cdot 2$ & $14 \cdot 2$ & $32 \cdot 8$ \\
\hline Milk & $1 \cdot 2$ & Skimmed milk & $0 \cdot 1$ & 7.9 & $10 \cdot 1$ & $9 \cdot 6$ & $9 \cdot 2$ & $42 \cdot 0$ \\
\hline Meat (for sandwiches) & 9.4 & Chicken filet (cold cut) & 1.4 & 6.4 & 8.4 & $6 \cdot 7$ & $7 \cdot 2$ & $49 \cdot 2$ \\
\hline Baking and frying fat & 31.8 & Liquid baking and frying fat & 8.0 & 7.5 & 5.9 & $6 \cdot 3$ & 6.5 & $55 \cdot 7$ \\
\hline Bread spread (butter, margarine) & $14 \cdot 6$ & Low-fat margarine & $5 \cdot 0$ & 3.5 & 5.9 & $7 \cdot 3$ & $5 \cdot 6$ & 61.3 \\
\hline Pastry & $7 \cdot 2$ & Fruit pie & 2.4 & $2 \cdot 7$ & 3.7 & $2 \cdot 8$ & $3 \cdot 1$ & 64.4 \\
\hline Biscuit (small) & $10 \cdot 4$ & Lady finger biscuits & 1.0 & $2 \cdot 0$ & 2.5 & 4.4 & $3 \cdot 0$ & $67 \cdot 4$ \\
\hline Warm bread-based snack & $11 \cdot 1$ & $\begin{array}{l}\text { Roll with } \\
\text { meat filling (Bapao) }\end{array}$ & 0.5 & 3.7 & 3.6 & 1.5 & 2.9 & $70 \cdot 3$ \\
\hline Crisps & 7.5 & Low-fat crisps & $2 \cdot 0$ & 1.9 & $2 \cdot 1$ & $3 \cdot 1$ & $2 \cdot 4$ & $72 \cdot 7$ \\
\hline Deep-frying fat & $21 \cdot 0$ & Liquid deep-frying fat & $9 \cdot 0$ & 1.7 & 2.9 & $2 \cdot 3$ & $2 \cdot 3$ & $75 \cdot 0$ \\
\hline Non-Dutch cheese & $19 \cdot 4$ & Low-fat Brie & $9 \cdot 0$ & $2 \cdot 8$ & $2 \cdot 3$ & $1 \cdot 3$ & $2 \cdot 1$ & $77 \cdot 1$ \\
\hline Ice-cream & $8 \cdot 0$ & Low-fat ice-cream & 1.0 & $2 \cdot 1$ & 2.0 & 1.9 & $2 \cdot 0$ & $79 \cdot 1$ \\
\hline $\begin{array}{l}\text { Chocolate sprinkles } \\
\text { (on sandwiches) }\end{array}$ & $9 \cdot 6$ & Fruit-flavoured sprinkles & 0.0 & 0.9 & $1 \cdot 6$ & $3 \cdot 1$ & 1.9 & $81 \cdot 0$ \\
\hline Biscuit (large) & $9 \cdot 8$ & Sponge cake & 0.5 & 1.2 & 1.3 & $2 \cdot 5$ & 1.7 & $82 \cdot 7$ \\
\hline Candy bar & 11.5 & Muesli-based chocolate-flavoured bar & 4.5 & 0.8 & 1.1 & $2 \cdot 7$ & 1.5 & $84 \cdot 2$ \\
\hline Dutch cheese spread & $14 \cdot 2$ & Low-fat cheese spread & 4.0 & 1.9 & 1.5 & 0.9 & 1.4 & $85 \cdot 6$ \\
\hline Chocolate & $20 \cdot 0$ & Chocolate bar with air bubbles & $18 \cdot 1$ & 1.2 & 1.3 & 1.6 & 1.4 & $87 \cdot 0$ \\
\hline Condensed milk & $9 \cdot 6$ & Skimmed condensed milk & 0.0 & 0.8 & 1.1 & 1.9 & 1.2 & $88 \cdot 2$ \\
\hline Custard and Bavarois desserts & $2 \cdot 1$ & Skimmed vanilla custard & $0 \cdot 1$ & 0.4 & 0.7 & $2 \cdot 4$ & $1 \cdot 2$ & 89.4 \\
\hline Whipped cream (prepared) & $18 \cdot 7$ & Low-fat prepared whipped cream & $16 \cdot 9$ & 0.7 & 1.1 & $1 \cdot 1$ & 0.9 & $90 \cdot 3$ \\
\hline Cake & 7.4 & Sponge cake & 0.5 & 0.1 & 0.8 & 1.7 & 0.9 & $91 \cdot 2$ \\
\hline $\begin{array}{l}\text { Fried potato product } \\
\text { (pre-cooked) }\end{array}$ & $2 \cdot 4$ & Low-fat French fries§ & 0.4 & 0.0 & 0.7 & 1.9 & 0.8 & $92 \cdot 0$ \\
\hline Peanut butter & $10 \cdot 3$ & Low-fat peanut butter & 7.9 & 0.3 & 0.9 & $1 \cdot 1$ & 0.8 & $92 \cdot 8$ \\
\hline Drinking chocolate & 1.4 & Low-fat drinking chocolate & 0.2 & 0.7 & 0.7 & 0.8 & 0.7 & 93.5 \\
\hline Nuts & 8.9 & Japanese rice savoury snack & 0.3 & 0.4 & 0.7 & 0.9 & 0.7 & 94.2 \\
\hline Yoghurt & 0.8 & Skimmed yoghurt & 0.0 & 0.3 & 1.1 & 0.4 & 0.6 & 94.8 \\
\hline Satay sauce (peanut sauce) & 3.5 & Low-fat satay sauce & 1.0 & 0.1 & 0.4 & $1 \cdot 1$ & 0.5 & $95 \cdot 3$ \\
\hline Soft curd cheese & $3 \cdot 6$ & Low-fat soft curd cheese & $3 \cdot 0$ & 0.0 & 0.8 & $0 \cdot 8$ & 0.5 & $95 \cdot 8$ \\
\hline Crackers/toasts & $4 \cdot 1$ & Low-fat crackers & 0.5 & 0.0 & 0.7 & 0.3 & 0.3 & $96 \cdot 1$ \\
\hline Chocolate mousse & 8.4 & Low-fat chocolate mousse & 0.8 & 0.1 & 0.5 & 0.3 & 0.3 & $96 \cdot 4$ \\
\hline Gravy & $10 \cdot 4$ & Low-fat gravy & $0 \cdot 1$ & 0.0 & 0.4 & 0.4 & 0.3 & $96 \cdot 7$ \\
\hline Fried potato products (prepared) & 3.8 & Low-fat French fries§ & $7 \cdot 3$ & 0.1 & 0.1 & 0.4 & 0.2 & $96 \cdot 9$ \\
\hline Cooking cream & $21 \cdot 3$ & Low-fat cooking cream & 15 & 0.5 & 0.1 & 0.0 & 0.2 & $97 \cdot 1$ \\
\hline Deep-fried fish in batter or crust & 4.5 & Pollack filet & 3.0 & 0.3 & 0.3 & 0.1 & 0.2 & $97 \cdot 3$ \\
\hline Whipped cream (unprepared) & $21 \cdot 7$ & Low-fat unprepared whipped cream & $7 \cdot 2$ & 0.0 & 0.3 & 0.3 & 0.2 & 97.5 \\
\hline Non-Dutch cheese spread & $22 \cdot 5$ & Cottage cheese & $2 \cdot 6$ & 0.1 & 0.3 & 0.1 & 0.2 & $97 \cdot 7$ \\
\hline Mayonnaise & $6 \cdot 1$ & Low-fat mayonnaise & 4.0 & 0.0 & 0.0 & 0.4 & $0 \cdot 1$ & $97 \cdot 8$ \\
\hline Vegetable soup & 0.9 & Low-fat vegetable soup & 0.2 & 0.0 & 0.0 & 0.4 & $0 \cdot 1$ & 97.9 \\
\hline Non-vegetarian soup (meat) & 0.9 & Chicken soup & 0.3 & 0.0 & 0.1 & 0.3 & 0.1 & 98.0 \\
\hline Rest & & No replacement & & $1 \cdot 1$ & 1.7 & $3 \cdot 1$ & $2 \cdot 0$ & $100 \cdot 0$ \\
\hline Total & & & & 100 & 100 & 100 & & \\
\hline
\end{tabular}

* Percentage of replacements per product group for 1st, 2nd and 3rd replaced product.

† Weighted mean of $g$ saturated fat per product group.

$\ddagger \mathrm{A}$ list of product names and a list of producers are available from the corresponding author.

$\S$ One alternative product was used for fried potato products in both pre-cooked (unprepared) and fried (prepared) states. Changes in fat content resulting from preparation were accounted for. 
for a product group, the product with the lowest saturated fat content per $100 \mathrm{~g}$ product was chosen. Suitability of the selected alternatives to replace the products in each product group was evaluated by the authors. Information on saturated fat $(\mathrm{g})$ and energy $(\mathrm{kJ})$ per $100 \mathrm{~g}$ of all alternative products was included in the data file. Wherever available, the product information was acquired from the 2001 Dutch food composition table. Information on the nutrient composition of alternative products not included in the 2001 table were retrieved from the 2006 table, from nutrition label information on the packages, or directly from the producers ${ }^{(12,13)}$. For the product group of chocolate, no suitable alternative product was available that featured lower levels of saturated fat, without differing in other product characteristics and purpose. Therefore, we selected an alternative product that offered the same volume but less weight per portion. All alternative products that we selected are listed in Table 1.

\section{Data analysis}

We started by calculating the mean intake of saturated fat from each product consumed for each participant, by multiplying the amount consumed by the saturated fat content of the product $(\mathrm{g} / 100 \mathrm{~g})$. The three products that contributed most to the intake of saturated fat were ranked in order of diminishing contribution for each participant. If more than one of these three products belonged to the same product group, the least consumed product was removed and replaced by the next product in line, until three products belonging to different product groups were left. This procedure was chosen to prevent replacement of multiple products by one single alternative product, which would reduce food variety. In eighty-nine cases, it turned out to be necessary to shift to the next-highest supplier of saturated fat.

The three products were consecutively replaced by their corresponding alternative products. Mean en $\%$ from saturated fat and total energy intake $(\mathrm{kJ})$ per $\mathrm{d}$, as well as the percentage of participants meeting the recommendation for saturated fat intake, were calculated before and after each additional replacement.

For all but one product group, replacement was based on the quantity of product originally consumed, i.e. the amount (in g) of the original product consumed was replaced by exactly the same amount of the alternative product. For the product group of chocolate, however, replacement was based on standard product portion.

The difference in fat content between the original products and the alternative was assessed by computing mean saturated fat content per $100 \mathrm{~g}$ for each product group. Data were analysed using the SPSS 13.0 statistical package (SPSS Inc., Chicago, IL, USA).

\section{Results}

Response and sample characteristics

The 2003 Dutch food consumption survey was conducted among 750 (response rate $42 \%$ ) participants aged 19-30 (mean 25.0 (SD 3.6)) years; $53.1 \%$ were women. Of the participants, $24.7 \%$ had a low level of education (none, primary education or preparatory secondary vocational education),
$46.7 \%$ a medium level (senior secondary vocational education or university preparatory education) and $28.7 \%$ a high level (higher professional education or university). The sample characteristics and results of the survey have been described in detail elsewhere ${ }^{(2)}$.

\section{Products, product groups and alternatives low in saturated fat}

A total of 231 different products were identified to be in the participants' top three suppliers of saturated fat. Sixteen of the top three products were omitted from the analysis. In seven cases, this was because no suitable alternative was found: eggs (four participants), coconut bread (two participants), bread (sixteen participants), pancakes (four participants), muesli (two participants), prawn crackers (two participants) and bread/pizza dough (six participants).

In another nine cases, i.e. coconut, porridge, oatmeal, buttermilk, semolina, liquid breakfast, chocolate (truffles), chicken nuggets, and granola bars, the reason for omitting them was a combination of two factors. On the one hand, their distinctive taste or product properties made it impossible to include these products in other, existing, product groups. On the other hand, each of these products was included in only a single participant's top three suppliers of saturated fat.

The omitted products were part of the top three for fortyfive participants. The remaining products were divided into forty product groups, with a single alternative for each group (Table 1).

A total of $42.0 \%$ of all replacements that we implemented related to the product groups of Dutch cheese, meats, and milks (Table 1). For most product groups, including the three most frequently replaced groups, alternatives were found that differed substantially in saturated fat content. In other, less frequently replaced product groups, for example, whipped cream, the difference between the weighted mean saturated fat content of the originally consumed products and the saturated fat content of the alternative was less substantial (Table 1).

\section{Results of replacement}

Table 2 shows that $23.3 \%$ of the participants had already met the recommended level of saturated fat intake of less than 10 en $\%$ on the two recalled days. Replacement of only the highest ranked product resulted in a mean reduction of 2.4 en $\%$ from saturated fat and in an additional $27.3 \%$ of the participants meeting the recommendation regarding saturated fat. The second replacement resulted in an additional mean reduction of $1.5 \mathrm{en} \%$ from saturated fat and in an additional $21.8 \%$ of the participants meeting the recommendation. The third replacement resulted in an average additional reduction of $1.1 \mathrm{en} \%$ from saturated fat and in an additional $13.0 \%$ of the participants meeting the recommendation.

The three product replacements together resulted in a mean reduction of $13.4 \mathrm{~g}$ saturated fat or $5.0 \mathrm{en} \%$ from saturated fat and in an additional $63.2 \%$ of the participants meeting the recommendation ( $<10$ en $\%$ from saturated fat), bringing the total percentage of participants meeting the recommendation in this simulation to $86 \%$.

The average intake of total energy was reduced by $156 \mathrm{~kJ}$ after the first replacement, while the replacement of the 
second highest ranked supplier of saturated fat yielded a mean reduction of $76 \mathrm{~kJ}$ and the replacement of the third highest supplier yielded an additional reduction of $78 \mathrm{~kJ}$. In sum, the mean reduction in total energy intake after all three replacements was $310 \mathrm{~kJ}$.

\section{Discussion}

The present study simulated the replacement by alternatives of up to three products contributing most to saturated fat intake in the daily diet, and assessed the effect of this strategy on the intake of saturated fat and total energy. Results showed that even one replacement (only the product ranked first in the list of suppliers of saturated fats) led to a considerable decline in saturated fat intake. After replacement of three products, the percentage of participants who met the Dutch recommendation for saturated fat intake rose from $23.3 \%$ to a vast majority of $86 \%$. (The reported percentage of participants meeting the recommendation for saturated fat intake deviates from data from the original report on the Dutch food consumption survey $^{(2)}$, because that report estimated habitual population intake distribution by correction for within-individual variation.) These effects are very large, and would have a substantial public health impact. They might, for instance, contribute to lower serum cholesterol levels and to a lesser degree also to lower obesity rates, due to the reduced mean total energy intake. The present study indicates that a relatively small number of changes in the diet could theoretically lead to substantial favourable changes in macronutrient and energy intake, and is therefore in line with earlier findings concerning total fat reduction through product replacements.

Corroborating findings from other studies, we showed that consumption of products from three product groups had a high impact on the consumption of saturated fat. For $42 \%$ of the sample, the top three suppliers of saturated fat came from three product groups, namely Dutch hard cheese, meats, and milk. Therefore, a targeted intervention that takes account of inter-personal differences is expected to have more effect than a generic approach that only aims at replacements in these three product groups, because the remaining $58 \%$ of the replacements came from thirty-seven different product groups.
Another useful finding was that alternatives for products high in saturated fat were available in the Netherlands for almost all product groups, but most importantly for the most frequently consumed product groups with a high saturated fat content.

Although these simulation results are promising, field studies are needed to test the feasibility and impact of the proposed strategy in real life. The type of data we used, as well as the simulation character of the present study, the type of alternatives used for the calculations, and the specific research population we studied imply some threats to the external validity of the present results. First of all, real-life replacements might differ from our simulation as subjects might not always manage to choose the alternative, or they might even completely relapse into their old habits. In addition, compensatory behaviour might occur. Individuals might consume larger quantities of the alternatives than of the original products or might start eating other products from the same or other product groups in addition to the alternatives, for instance due to the reduction in total energy intake that we found after the replacements. Although this reduction is favourable from the perspective of overweight prevention, it might be preferable to select and recommend alternatives with reduced saturated fat, but comparable energy, to prevent individuals from eliminating the effect on saturated fat intake by compensatory behaviour. Compensatory behaviour across product groups might also occur to compensate for the loss in taste. On the other hand, an earlier study found that the use of solely lean products in one product group was only partially compensated by the increase in consumption of products from other product groups ${ }^{(8)}$. Similar results were found in the field experiments by Gatenby et al., and Weststrate et $a l$., where participants were found to show increased consumption of other macronutrients, while nevertheless consolidating the reduction in energy intake from fat over time ${ }^{(8,10)}$.

Another threat to the external validity of the proposed strategy is that we selected rather extreme alternatives (although available in Dutch supermarkets), effecting the largest possible reduction in saturated fat content. We did not take aspects of product acceptability into consideration. For example, in the category of Dutch hard cheeses, a product containing $6.2 \%$ total fat $(4.2 \%$ saturated) was selected to replace a full-fat cheese (Goudse $48+$ ) containing $31.2 \%$ total fat

Table 2. Consumption of saturated fat by percentage energy (en\%) and energy (kJ), cumulative mean reduction of saturated fat (en\%) and energy $(\mathrm{kJ})$, and cumulative percentage of participants meeting the recommendation regarding saturated fat consumption $(<10$ en\%), in the initial situation and after each additional replacement, in a simulation of product replacements in Dutch young adults

(Mean values and standard deviations)

\begin{tabular}{|c|c|c|c|c|c|c|c|c|c|c|}
\hline & \multicolumn{4}{|c|}{ Saturated fat } & \multicolumn{4}{|c|}{ Energy } & & \\
\hline & \multicolumn{2}{|c|}{ Intake (en\%) } & \multicolumn{2}{|c|}{$\begin{array}{l}\text { Cumulative } \\
\text { reduction } \\
\text { (en\%) }\end{array}$} & \multicolumn{2}{|c|}{ Intake (kJ) } & \multicolumn{2}{|c|}{$\begin{array}{l}\text { Cumulative } \\
\text { reduction }(\mathrm{kJ})\end{array}$} & \multicolumn{2}{|c|}{$\begin{array}{l}\text { Participants consuming }<10 \mathrm{en} \% \\
\text { from saturated fat }\end{array}$} \\
\hline & Mean & SD & Mean & SD & Mean & SD & Mean & SD & Cumulative \% & $\begin{array}{l}\text { Additional \% after } \\
\text { each product replacement }\end{array}$ \\
\hline Initial situation & 12.4 & 3.4 & - & - & 10098 & 3245 & - & - & $23 \cdot 3$ & - \\
\hline After first replacement & $10 \cdot 0$ & 2.9 & $2 \cdot 4$ & 1.4 & 9943 & 3226 & 156 & 508 & $50 \cdot 6$ & $27 \cdot 3$ \\
\hline After two replacements & 8.5 & $2 \cdot 7$ & 3.9 & 1.8 & 9866 & 3222 & 232 & 618 & $72 \cdot 5$ & 21.9 \\
\hline After three replacements & 7.5 & $2 \cdot 4$ & 4.9 & $2 \cdot 0$ & 9789 & 3189 & 310 & 658 & $86 \cdot 3$ & $13 \cdot 8$ \\
\hline
\end{tabular}


(19.8\% saturated). This difference in fat content between the cheeses is large and may not be acceptable at all because of major differences in taste. Selection of less extreme alternative products such as a $30+$ cheese, a product containing $17.6 \%$ total fat $(11.2 \%$ saturated $)$ or a $20+$ cheese with $11.9 \%$ total fat $(7.6 \%$ saturated) would yield a smaller reduction in saturated fat intake, but might be a more acceptable alternative. Another aspect that we did not take into account was the overall healthfulness of the alternative products. We only considered energy intake and did not measure the effects on the intake of other nutrients. That would be a relevant and challenging extension of the present study, and link up with the current shift from nutrient-specific recommendations to food- and food pattern-oriented recommendations, resulting from the fact that nutrition-related health problems are nowadays more strongly related to foods and food patterns than to nutrients $^{(14)}$.

Another limitation of the present study that needs to be addressed is that the study was conducted among young adults only. We cannot generalise the present results beyond this group, because eating habits are known to differ between age groups ${ }^{(2)}$. Finally, the simulation did not use a measure of habitual intake, but the average consumption measured on two recall days. The present study thus only allows us to learn about the potential effects on reduction of saturated fat intake for the two recall days, and not about the potential effects on habitual intake.

We conclude that replacing a few influential high-saturated fat products by available lower-fat alternatives can significantly reduce saturated fat intake and increase the proportion of individuals complying with recommended intsake levels. Findings in this simulation study are promising enough to proceed with field experiments to assess the feasibility and impact of the replacement strategy in 'real life'.

\section{Acknowledgements}

The authors are thankful for Janneke van den Bergh's contribution to the preparation of the present study and the selection of alternatives low in saturated fat.

The present study was supported by funds from ZonMw (the Netherlands Organization for Health Research and Development), grant no. 40050012.

P. v. A. and B. S. designed the study, J. V.-K. and M. C. O. provided the dataset, and B. S. conducted the analysis. All authors significantly contributed to the drafting of the paper.

The authors do not have any financial or personal conflicts of interest.

\section{References}

1. Health Council of the Netherlands (2006) Guidelines for a Healthy Diet 2006. Publication no. 2006/21E. The Hague, the Netherlands: Health Council of the Netherlands.

2. Hulshof KFAM, Ocké MC, Van Rossum CTM, et al., (2004) Resultaten van de Voedselconsumptiepeiling 2003 (Results of the 2003 National Food Consumption Survey). RIVM report 350030002. Bilthoven, the Netherlands: RIVM.

3. World Health Organization (2003) Diet, Nutrition and the Prevention of Chronic Diseases. Joint WHO/FAO Expert Consultation. WHO Technical Report Series no. 916. Geneva: WHO.

4. Van Kreijl CF, Knaap AGAC \& Van Raaij JMA, editors (2006) Our Food, our Health. Healthy Diet and Safe Food in the Netherlands. RIVM report 270555009. Bilthoven, the Netherlands: RIVM.

5. Morgan R, Sigman-Grant M, Taylor DS, et al. (1997) Impact of macronutrient substitutes on the composition of the diet and the U.S. food supply. Ann N Y Acad Sci 819, 70-95.

6. Kistemaker C (1991) Simulatiestudie Aangaande de Invloed op de Vetconsumptie van Vervanging van Vetrijke Producten door Magere Alternatieven, bij 22-49 Jarigen (Simulation Study Regarding the Influence on Fat Intake of Replacing High-Fat Products by Lean Alternatives, Among 22-49 Year Olds). Report V91.360. Zeist, the Netherlands: TNO-Voeding.

7. Kistemaker C, Löwik MRH \& Wedel M, et al. (1991) Compensatiemechanismen met Betrekking tot de Consumptie van Vetarme Produkten bij 22-49 Jarige Mannen (Compensation Mechanism Regarding the Intake of Low-Fat Products Among 22-49 Year Old Males). Report V9.093. Zeist, the Netherlands: TNO-Voeding.

8. Gatenby SJ, Aaron JI, Morton GM, et al. (1995) Nutritional implications of reduced-fat food use by free-living consumers. Appetite 25, 241-252.

9. Reger-Nash B, Wootan MG, Booth-Butterfield S, et al. (2005) The cost-effectiveness of $1 \%$ or less media campaigns promoting low-fat milk consumption. Prev Chronic Dis 2, A05.

10. Weststrate JA, Van het Hof KH, Van den Berg H, et al. (1998) A comparison of the effect of free access to reduced-fat products or their full fat equivalents on food intake, body weight, blood lipids and fat-soluble antioxidants levels and haemostasis variables. Eur J Clin Nutr 52, 389-395.

11. Slimani N, Ferrari P, Ocké M, et al. (2000) Standardization of the 24-hour diet recall calibration method used in the European Prospective Investigation into Cancer and Nutrition (EPIC): general concepts and preliminary results. Eur J Clin Nutr 54, 900-917.

12. Stichting Nederlands Voedingsstoffenbestand (2001) NEVOtabel 2001: Nederlands Voedingsstoffenbestand 2001 (Dutch Food Composition Table 2001). The Hague: Dutch Nutrition Centre.

13. Stichting Nederlands Voedingsstoffenbestand (2006) NEVO-tabel 2006: Nederlands Voedingsstoffenbestand 2006 (Dutch Food Composition Table 2006). The Hague: Dutch Nutrition Centre.

14. Bere E \& Brug J (2008) Towards health-promoting and environmentally friendly regional diets - a Nordic example. Public Health Nutr (epublication ahead of print version 14 March 2008). 